\title{
EDITORIAL
}

\section{"PATRIA ES HUMANIDAD"}

\author{
Pablo Guadarrama González * \\ Universidad Católica de Colombia
}

DOI: http://dx.doi.org/10.14718/CulturaLatinoam.2020.31.1.1

Estos no son tiempos de abstractas reflexiones metafísicas, sino de "humanismo práctico". Cultura Latinoamericana desea contribuir a esa labor desde su trinchera de ideas, que, como expresara José Martí, vale más que trinchera de piedras.

El elemental deber de los intelectuales es contribuir al análisis crítico de la realidad, del mundo en que viven, armados de las mejores ideas que han ido heredando de otras generaciones; pero también, contribuyendo de algún modo al enriquecimiento del arsenal teórico con que cuentan los pueblos para emanciparse de todo tipo de dominación, que no excluye la del miedo.

Imbuidos del criterio de Einstein, según el cual "no hay nada más práctico que una buena teoría”, se debe asumir una postura de gramsciana organicidad intelectual para reflexionar críticamente sobre la situación producida por la pandemia de la COVID-19, por un lado, y por otro, por la pandemia de confrontación ideológica ante las distintas posiciones asumidas ante la primera.

En ocasión anterior pretendimos definir el humanismo como "una postura de compromiso activo, militante y arriesgado con la defensa de la dignidad de determinados grupos humanos, que se diferencia

\footnotetext{
* Doctor en Filosofía (Leipzig). Doctor en Ciencias (Cuba). Académico titular de la Academia de Ciencias de Cuba. Profesor Emérito de la Universidad Central "Marta Abreu" de Las Villas (Cuba). Investigador Senior (Colciencias), actualmente es profesor de la Maestría Internacional en Ciencias Políticas (convenio Universidad Católica de Colombia- Universidad de Salerno). ORCID: https:// orcid.org/0000-0002-4776-2219. Contacto: pabloguadarrama@gmail.com
}

Referencia: Guadarrama González, P. (2020). Editorial. "Patria es humanidad". Cultura Latinoamericana, 31 (1), pp. 17-20. DOI: http://dx.doi.org/10.14718/ CulturaLatinoam.2020.31.1.1 
del humanismo abstracto que se limita a simples declaraciones filantrópicas, que no trascienden más allá de cierta misericordia o postura piadosa ante indígenas, esclavos, siervos, proletarios, mujeres, niños, minusválidos, etc. Un humanismo práctico debe distanciarse del antropocentrismo que ha caracterizado generalmente a la cultura occidental y tomar en consideración la imprescindible interdependencia entre el hombre y la naturaleza" (Guadarrama, 2006, pp. 209).

Pero en estos momentos, cuando no es una clase social o un grupo determinado de personas, sino la humanidad entera la que se encuentra amenazada, tal tipo de humanismo no sería suficiente. Es más, en verdad resultaría inhumano si se limitase solo a la emancipación de un sector específico de la población, pues todos, independientemente del estrato socioeconómico, etnia, género, generación, etc., tenemos posibilidad de contagiarnos.

Tal vez no se había experimentado nunca antes, ni incluso en los más conflictivos años de la guerra fría, la conflictividad entre la ideología que prioriza salvar las economías y la que, en su lugar, otorga mayor importancia a las vidas humanas.

Los defensores de la primera opción no dejarán de argumentar que sin economía no es posible asegurar la salud pública. Los proponentes de la segunda consideramos que si se hubiesen tomado a tiempo las adecuadas medidas de control — como lo hizo China, oportunamente, a pesar de las frecuentes críticas por violar las "libertades individuales" de los ciudadanos al encerrarlos; algo que ahora hacen hasta los mismos que criticaron-, hubiera podido haberse controlado la epidemia y se hubiera evitado su mayor propagación, y de ese modo, a la larga, se hubiese podido salvar en mejores condiciones la economía.

Este es también un momento muy evidente de confrontaciones ideológicas y filosóficas entre quienes defienden la existencia de una insuperable "naturaleza humana", egoísta e individualista, estimuladora del sálvese él que pueda en esta jungla de asfalto, y quienes consideramos que este es un criterio biologicista ya superado, pues en verdad la "condición humana", aunque contradictoria, es eminentemente social y solidaria (Guadarrama, 2010).

$\mathrm{El}$ individualismo está puesto a prueba, como nunca, en estos pandémicos tiempos. Algunos de forma irresponsable violan las medidas de control establecidas y han hecho peligrar no solo su propia vida, sino la de sus familias, amigos y colegas. Y llegan incluso a expresar que no les importa arriesgarse y hasta morir. Marx criticaba a Kierkegaard por proponer el suicidio como vía para solucionar los conflictos, y le replicaba que cada individuo humano es un representante de 
toda la humanidad, pues esta no existe en abstracto ni en un platónico topos urano, sino en cada uno de nosotros. Por ello, cualquier atentado contra un individuo humano lo es contra la humanidad entera.

Numerosos escritores de ficción han anticipado situaciones algo similares a las actuales. Por lo general, su postura humanista les ha permitido salir de la zozobra del pesimismo.

Es común recordar en estos días La peste, de Camus —especialmente el optimismo vital de su existencialismo, que hoy debe animarnos-, cuando expresó: "Donde no hay esperanza, debemos inventarla". La ceguera, de Saramago, concluye felizmente cuando se supera la pandemia, pero es el momento de reflexión y se preguntan: "Por qué nos hemos quedado ciegos, No lo sé, quizá un día lleguemos a saber la razón, Quieres que te diga lo que estoy pensando, Dime, Creo que no nos quedamos ciegos, creo que estamos ciegos, Ciegos que ven, Ciegos que, viendo, no ven”. Lamentablemente, ese ha sido el caso de algunos gobernantes.

La peste también abrumó a los habitantes de Macondo, pero para García Márquez "Un hombre solo tiene derecho a mirar a otro hacia abajo, cuando ha de ayudarle a levantarse" ${ }^{1}$. Por eso es reprochable abandonar a un enfermo o negarle alimentos y medicinas a un pueblo; por el contrario, corren tiempos de solidaridad y "humanismo práctico", no de simples declaraciones filantrópicas.

Han sorprendido noticias de agresiones físicas a enfermos y de exacerbada xenofobia. Pero alientan otras como las referidas al crucero británico al que se le negó desembarcar a sus pasajeros, entre ellos algunos enfermos, en varios países caribeños; mientras un pueblo bloqueado por la potencia imperial — que desconoce durante varios años los reclamos de la absoluta mayoría de la asambleas generales de la ONU— los recibió y posibilitó que todos regresaran debidamente a sus casas. La solidaridad humana se ha puesto a prueba una vez más. Se ha evidenciado que se debe confiar en ella al ver médicos chinos y cubanos llegar a Lombardía para colaborar o aviones rusos y alemanes aterrizar con medicamentos, equipos y personal calificado para salvar vidas en Italia.

"Patria es humanidad", aseveró José Martí. Ahora se confirman de nuevo la validez de esas palabras.

La historia al final dirá quiénes tuvieron la razón: los que priorizaron la economía o la vida humana, si al menos sobrevivieron para

1. https://www.semana.com/mundo/articulo/johnny-welch-escribio-un-poema-que-le-achacangabriel-garcia-marquez/384704-3 
contarla. Las noticias llegadas de Wuhan levantando la cuarentena han sido alentadoras para los que nos resistimos a aceptar que el hombre sea el lobo del hombre. Si fuese así, la humanidad hubiese desaparecido mucho antes, como se percató hasta el socialdarwinista Herbert Spencer.

Ante esa crucial disyuntiva, los que consagramos nuestras vidas a la docencia y a la investigación estamos obligados a plantearnos cuál debe ser nuestro papel al respecto. ¿Será asumir la falaz neutralidad axiológica weberiana y cruzarnos de brazos como expresión de impotencia o, por el contrario, estimular desde el aula y en nuestras investigaciones el optimismo epistemológico y axiológico de confianza en la perfectibilidad humana? Estamos obligados, por imperativo categórico, a sembrarlo en el ser humano, sobre todo en las nuevas generaciones, destinadas a practicar el humanismo y la solidaridad mucho más que las antecesoras. Esta actitud deberán asumirla sin discriminaciones de ningún tipo, tomando kantianamente al hombre como fin y nunca como medio.

\section{Referencias}

Guadarrama, P. (2006). Humanismo y marxismo. En J. Estrada (Comp.), Teoría y acción política en el capitalismo actual (pp. 209226). Bogotá: Universidad Nacional de Colombia - Seminario internacional Marx vive.

Guadarrama, P. (2010). Introducción. En P. Guadarrama (Coord.), La condición bumana en el pensamiento cubano del siglo XX (pp. 1-14). La Habana: Editorial de Ciencias Sociales. 